\title{
REPENSANDO LOS EFECTOS DE LA SEPARACIÓN DE PATRIMONIOS Y LA SUCESIÓN DEL CÓNYUGE
}

\author{
REVIEWING THE EFFECTS OF THE \\ SEPARATION OF HERITAGE AND THE \\ SUCCESSION OF THE SPOUSE
}

Mario CAstillo Freyre*

WWW.CASTILLOFREYRE.COM

Magíster y Doctor en Derecho, Abogado en ejercicio, socio del Estudio que lleva su nombre; Docente principal en la Pontificia Universidad Católica del Perú y en la Universidad Femenina del Sagrado Corazón. Miembro de Número de la Academia Peruana de Derecho. Director de las colecciones Biblioteca de Arbitraje y Biblioteca de Derecho de su Estudio. Decano de la Facultad de Derecho de la Universidad Católica San Pablo de Arequipa.

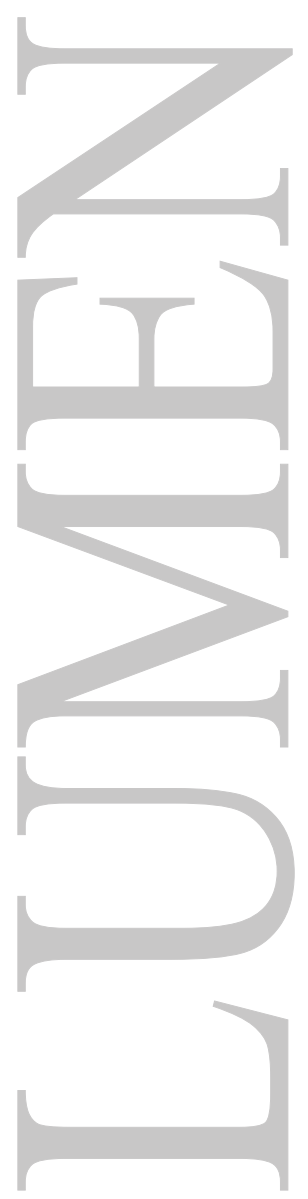




\title{
REPENSANDO LOS EFECTOS DE LA SEPARACIÓN DE PATRIMONIOS Y LA SUCESIÓN DEL CÓNYUGE
}

\author{
REVIEWING THE EFFECTS OF THE SEPARATION OF HERITAGE AND \\ THE SUCCESSION OF THE SPOUSE
}

Mario Castillo Freyre

\begin{abstract}
RESUMEN:
En el presente artículo se efectúa un análisis de los efectos de la separación de patrimonios y la sucesión del cónyuge. La idea tradicional es que cuando dos personas contraen matrimonio, no sólo deben unir sus vidas en los aspectos extrapatrimoniales, sino también en aquéllos de orden patrimonial. La sociedad de gananciales tiene como objetivo central que el grueso de los bienes que se adquieran en el futuro, salvo determinadas excepciones, sean considerados como bienes comunes. En ese sentido, a partir del momento de la celebración del matrimonio, la generalidad de bienes que adquieran los cónyuges, en estricto, no serán de propiedad de cada uno de ellos, sino de la sociedad de gananciales. De esta forma, por más que uno en solitario adquiera un bien, tal bien no le pertenecerá a él, sino a la denominada sociedad de gananciales, y tendrá la calidad de bien común jurídicamente distinto al patrimonio de cada uno de ellos.
\end{abstract}

Lo que se propone en el presente artículo es que el régimen de separación de patrimonios pueda sufrir una modificación legislativa, que implique agregar una opción al mismo, que consistiría en que la separación de patrimonios se siga manteniendo después de la muerte del titular de dicho patrimonio. Ello significa que, de optarse por este camino, los cónyuges podrían convenir casarse bajo separación de patrimonios y también renunciar a suceder entre sí.

\section{PALABRAS CLAVE:}

Separación de Patrimonios; Sucesión del cónyuge; Sociedad de Gananciales; Régimen patrimonial.

\begin{abstract}
:
In this article an analysis is made of the effects of the separation of assets and the succession of the spouse. The traditional idea is that when two people marry, they must not only unite their lives in extra-patrimonial aspects, but also in those of patrimonial order. The community society has as its central objective that the bulk of the goods acquired in the future, with certain exceptions, be considered as common goods. In that sense, it implies that, from the moment of the celebration of marriage, the generality of goods acquired by the spouses, in strict, will not be the property of each one of them, but of the community of acquisitions. In this way, no matter how much a single person acquires a good, such good will not belong to him, but to the so-called community of acquisitions, and will have the quality of a common good legally distinct from the patrimony of each one of them.
\end{abstract}

What is proposed in this article is that the regime of separation of assets may undergo a legislative amendment, which implies adding an option to it, which would consist in the separation of assets to be maintained after the death of the owner of said patrimony. This means that, in choosing this path, the spouses could agree to marry under separation of patrimonies and also to renounce each other.

\section{KEY WORDS:}

Separation of Patrimonies; Succession of the Spouse; Sociedad de Gananciales; Patrimonial Regime. 


\section{INTRODUCCION:}

\section{HISTORIA Y ANTECEDENTES DE ESTE ARTÍCULO}

Hace pocos días recibí la llamada telefónica de un ilustre hombre de derecho, ya retirado de la profesión por voluntad propia, quien de seguro es uno de los abogados que más éxito profesional tuvo en los tribunales civiles del Perú en la segunda mitad del siglo XX y principios del XXI. Yo no lo conocía, ya que en los años en que estudié en la Pontificia Universidad Católica del Perú, él, precisamente, se ausentó de la cátedra por algunos semestres.

Resulta que había leído un trabajo escrito por mí en el año 2013, a raíz de la promulgación de la Ley n. ${ }^{\circ} 30007,{ }^{1}$ publicada el 17 de abril de ese año, a través de la cual se estableció la modificación de una serie de artículos del Código Civil, que introducían como reforma, fundamentalmente, la condición de heredero forzoso para el integrante supérstite de la unión de hecho.

Conversamos alrededor de cuarenta minutos y me transmitió una serie de preocupaciones de mucha relevancia sobre la materia acerca de la cual versa este artículo, manifestándome que confiaba en que las procesaría adecuadamente. Le prometí que escribiría un artículo al respecto.

Lo hago con todo gusto y en homenaje a ese ilustrísimo abogado litigante, quien me pidió absoluto anonimato.

Por otra parte, debo decir que en el año 2004 escribí, conjuntamente con el brillante periodista y también notable hombre de derecho, Ricardo Vásquez Kunze, la obra titulada Analizando el análisis. Autopsia del análisis económico del derecho por el derecho civil. Dentro de los capítulos de dicho libro se encuentra uno titulado "Amor de gavilanes. Mujer, casos de la vida real: discriminación, disposición y gravamen de bienes sociales» ${ }^{2}$ en el cual mi coautor y yo analizamos algunos aspectos de la regulación actual de la separación de patrimonios.

En ese sentido, debo advertir que el presente artículo recoge también algunas de esas ideas, cuya autoría, obviamente, no me pertenecen en exclusiva.

\section{EL RÉGIMEN PATRIMONIAL DEL MATRIMONIO}

Constituye idea tradicional la de que cuando dos personas contraen matrimonio, no sólo deben unir sus vidas en los aspectos extrapatrimoniales, sino también en aquéllos de orden patrimonial.

Así, representa valor entendido que lo normal en una situación de esta naturaleza, es que tal pareja constituya a partir del inicio de su matrimonio, lo que se conoce con el nombre de una sociedad de gananciales.

La sociedad de gananciales tiene como objetivo central el que el grueso de los bienes que se adquieran en el futuro, salvo determinadas excepciones, sean considerados como bienes comunes. En ese sentido, implica que, a partir del momento de la celebración del matrimonio, la generalidad de bienes que adquieran los cónyuges, en estricto, no serán de propiedad de cada uno de ellos, sino de la sociedad de gananciales.

1 El trabajo se encuentra en: CASTILLO FREYRE, Mario. «La sucesión en las uniones de hecho». En Persona y familia. Revista del Instituto de la Familia-Facultad de Derecho. Lima: Universidad Femenina del Sagrado Corazón, 2013, n. ${ }^{\circ} 2(1)$, pp. 21-41.

2 CASTILLO FREYRE, Mario y Ricardo VÁSQUEZKUNZE. «Amor de gavilanes. Mujer, casos de la vida real: discriminación, disposición y gravamen de los bienes sociales». En Analizando el análisis. Autopsia del análisis económico del derecho por el derecho civil. Lima: Pontificia Universidad Católica del Perú-Estudio Mario Castillo Freyre, 2006. 
De esta forma, por más de que uno en solitario adquiera un bien, tal bien no le pertenecerá a él, sino a una entelequia denominada sociedad de gananciales, y tendrá la calidad de bien común, lo que no es sino una ficción que representa el patrimonio común de la sociedad conyugal, jurídicamente distinto al patrimonio de cada uno de ellos; tanto así, que los bienes que se adquieren para la sociedad conyugal, no se adquieren en condición de copropiedad, pues no pertenecen a ambos cónyuges en cuotas indivisas, sino a un patrimonio jurídico distinto, que es, precisamente, la sociedad de gananciales.

Esa situación constituye la regla, de manera tal que si los futuros cónyuges no establecen un régimen diferente antes de contraer matrimonio, será el de la sociedad de gananciales, aquél que rija su futura vida patrimonial.

De acuerdo a lo establecido por el artículo $301^{3}$ del Código Civil, en el régimen de sociedad de gananciales puede haber bienes propios de cada cónyuge y bienes de la sociedad; encargándose el artículo $302^{4}$ de establecer cuáles son los bienes propios, en tanto todos los demás se denominarán bienes sociales.

La idea de que el régimen patrimonial del matrimonio funcione de esta manera, se basa en la consideración de que es justo que los bienes adquiridos durante el matrimonio pertenezcan a ambos cónyuges, dado que el Derecho siempre ha asumido que en una relación tradicional, era el hombre el que realizaba un trabajo remunerado, mientras la mujer, antiguamente, no lo hacía y, más bien, se dedicaba al cuidado de la familia y las labores del hogar.

Sin embargo, debemos admitir que esto ha variado considerablemente en nuestros días, no sólo en el Perú sino en gran parte del mundo, ya que en tiempos modernos las mujeres también desarrollan actividades laborales fuera del hogar y además cumplen con la valiosísima tarea de ser el centro de organización de sus respectivos hogares.

Dentro de tal orden de ideas, el rol de la mujer en la sociedad ha variado notablemente, convirtiéndose en elemento activo de la producción de bienes y servicios, y en agente económico importante para los ingresos del matrimonio.

Hoy es frecuente, incluso, ver parejas en las cuales es la mujer la que tiene ingresos mayores que el varón, y no resultan exóticos aquellos casos en los cuales, es la mujer la que trabaja fuera del hogar, y el hombre el que no lo hace y se dedica a las labores de la casa.

Todo esto, sin embargo, no nos permite decir que la mujer tiene una situación de igualdad laboral con respecto al hombre, pues existen determinadas situaciones, derivadas, fundamentalmente, de la maternidad, que dificultan la inserción de las mujeres en el mercado laboral.

3 «Artículo 301.- En el régimen de sociedad de gananciales puede haber bienes propios de cada cónyuge y bienes de la sociedad».

4 «Artículo 302.- Son bienes propios de cada cónyuge:

1. Los que aporte al iniciarse el régimen de sociedad de gananciales.

2. Los que adquiera durante la vigencia de dicho régimen a título oneroso, cuando la causa de adquisición ha precedido a aquélla.

3. Los que adquiera durante la vigencia del régimen a título gratuito.

4. La indemnización por accidentes o por seguros de vida, de daños personales o de enfermedades, deducidas las primas pagadas con bienes de la sociedad.

5. Los derechos de autor e inventor.

6. Los libros, instrumentos y útiles para el ejercicio de la profesión o trabajo, salvo que sean accesorios de una empresa que no tenga la calidad de bien propio.

7. Las acciones y las participaciones de sociedades que se distribuyan gratuitamente entre los socios por revaluación del patrimonio social, cuando esas acciones o participaciones sean bien propio.

8. La renta vitalicia a título gratuito y la convenida a título oneroso cuando la contraprestación constituye bien propio.

9. Los vestidos y objetos de uso personal, así como los diplomas, condecoraciones, correspondencia y recuerdos de familia». 
Sin embargo, éste es un tema que se ha ido superando con el paso de los años, y que encuentra a las mujeres, en la segunda década del siglo XXI, en una posición laboral mucho mejor que en cualquier momento de la historia de la humanidad.

No obstante, si nos ponemos a pensar en la lógica del régimen de sociedad de gananciales, ella resultará siempre vigente y aplicable, incluso para cuando ambos cónyuges trabajen, y para aquellos casos en los cuales sea sólo la mujer la que lo haga fuera del hogar.

La idea de proteger los intereses de la familia y, especialmente, los del cónyuge que no labore fuera de casa y no genere ingresos, siempre estará presente para sostener los argumentos que aborda la doctrina en favor de la existencia de la sociedad de gananciales.

No obstante lo señalado, nosotros consideramos que la sociedad de gananciales no constituye necesariamente la figura ideal para normar el régimen patrimonial de un matrimonio, y desde el año 2004, hemos propugnado la tesis de que la separación de patrimonios representa un mejor camino para los futuros cónyuges.

Este régimen patrimonial está regulado en los artículos 327 a 331 del Código Civil.

El artículo 327 establece que «en el régimen de separación de patrimonios, cada cónyuge conserva a plenitud, la propiedad, administración y disposición de sus bienes presentes y futuros, y le corresponden los frutos y productos de dichos bienes».

En tanto, el artículo 328 señala que: «cada cónyuge responde de sus deudas con sus propios bienes».

El momento ideal para pactar el régimen de separación de patrimonios es antes de la celebración del matrimonio, recurriendo, como lo establece el artículo $295^{5}$ del propio Código, a constituirlo por escritura pública, y el mismo comenzará a regir al celebrarse el matrimonio.

El requisito de escritura pública se establece bajo sanción de nulidad y tal régimen no surtirá efectos contra terceros, hasta que no se inscriba en el registro personal.

A nuestro juicio, queda claro que el régimen de separación de patrimonios, es más eficiente que el régimen de sociedad de gananciales; ello, por las siguientes razones:

a) Claridad. No cabe duda de que dentro de un régimen de separación de patrimonios, la división de los bienes en materia de propiedad, es sumamente clara, pues tales bienes, o pertenecerán en propiedad al marido o pertenecerán en propiedad a la mujer, no existiendo una tercera posibilidad.

Ello, a diferencia del régimen de sociedad de gananciales, en donde en muchos casos no resultará clara la ubicación de tales bienes, sea en el patrimonio de cualquiera de los cónyuges (en caso fuesen bienes propios), o en la condición de bienes comunes.

La calificación jurídica de los bienes resulta en extremo importante, sobre todo a efectos de la contratación con terceros, y de las seguridades que esos terceros pueden tener con respecto al patrimonio que respaldará el cumplimiento de las obligaciones contraídas por los cónyuges.

«Artículo 295.- Antes de la celebración del matrimonio, los futuros cónyuges pueden optar libremente por el régimen de sociedad de gananciales o por el de separación de patrimonios, el cual comenzará a regir al celebrarse el casamiento. Si los futuros cónyuges optan por el régimen de separación de patrimonios, deben otorgar escritura pública, bajo sanción de nulidad. Para que surta efecto debe inscribirse en el registro personal. A falta de escritura pública se presume que los interesados han optado por el régimen de sociedad de gananciales». 
Las obligaciones contraídas por cada uno de los cónyuges estarán respaldadas por el patrimonio del cónyuge que contraiga la obligación, pero también por el patrimonio de la sociedad de gananciales, específicamente en lo que respecta a los bienes comunes.

En ese sentido, si los bienes propios del cónyuge que ha asumido esa obligación a título personal, no fueran suficientes para responder por su cumplimiento, el acreedor podrá dirigirse contra la sociedad, pero no para cobrarse el íntegro de ella, ya que existirá el problema de que para cobrar las deudas contraídas por ese cónyuge, tendría que liquidarse la sociedad, y recién poder hacer efectivo el crédito con respecto a aquella porción patrimonial que resulte de dicha división y partición en favor del cónyuge deudor.

Como puede apreciarse, resulta mucho más fácil y expeditivo el cobro de una deuda contraída por uno de los cónyuges, en caso estemos en presencia de un régimen de separación de patrimonios, dado que al no existir la entelequia sociedad de gananciales y de los bienes comunes, el acreedor podrá dirigirse contra los bienes propios del cónyuge deudor, quien, obviamente, carecerá de bienes comunes en el matrimonio.

b) Incentivos. Cuando en el año 2004 Ricardo Vásquez y yo propusimos este punto, el mismo llamó la atención del medio jurídico por innovador, pero consideramos que en el régimen de separación de patrimonios, las reglas de juego se encuentran mucho más claras y definidas que en el de sociedad de gananciales, de modo tal que, desde antes del matrimonio, los futuros cónyuges sabrán que todo lo que adquiera en propiedad cada uno de ellos, será exclusivamente de él, y todos los ingresos que adquiera fruto de su trabajo o negocios, también le pertenecerán en exclusiva a él.

Esta realidad representa, sin duda, un incentivo para que, desde el principio, ambos cónyuges trabajen fuera del hogar y busquen obtener los mayores ingresos en beneficio propio y de la familia.

Estimamos que si la regla fuera la separación de patrimonios, las mujeres harían respetar mucho más su derecho a trabajar, y el que los roles en el hogar sean compartidos, pues en caso de no serlo, tal situación redundaría en el perjuicio económico presente y futuro de la mujer.

Con esto no estamos diciendo que el matrimonio se convierta en una suma de egoísmos.

Creo, más bien, que el régimen patrimonial del matrimonio se convertiría en una suma de previsiones, en donde si bien ambos cónyuges llevarían adelante con entusiasmo la empresa matrimonial, irían constituyendo una especie de «seguro», en caso llegue a fracasar el matrimonio, de modo tal que si esta situación indeseable se presentara en el futuro, cada uno de ellos habría hecho un patrimonio propio interesante, el mismo que resultaría, valga la redundancia, exclusivamente propio.

Ya bastantes problemas suscita la disolución de un matrimonio, y los mismos tienen, por lo general, como uno de sus ingredientes más importantes, el de la discusión relativa al patrimonio común, el que muchas veces se convierte en instrumento de chantaje y negociación, para lograr objetivos en torno a la tenencia de los hijos menores de edad.

Todo esto se evitaría o, al menos, se atenuaría considerablemente, si la regla no fuese la sociedad de gananciales, sino la separación de matrimonios.

El lector podrá preguntarse cuál sería la necesidad de invertir la regla, si es que los futuros contrayentes, pueden pactar antes del matrimonio, un régimen de separación de patrimonios. 
La razón es muy sencilla.

Cuando las parejas se casan por el régimen de separación de patrimonios, ello implica que, al menos uno de los futuros cónyuges, o incluso ambos, ya cuentan con un patrimonio propio que desean proteger y mantenerlo en su dominio exclusivo; de tal manera que en los casos en que hoy se acuerda la separación de patrimonios, probablemente nos encontremos frente a parejas que carezcan de interés por iniciar una sana competencia en el desarrollo de patrimonios autónomos, ya que o ambos ya cuentan con patrimonio, o alguno de ellos, simplemente, carecerá de interés alguno al respecto.

Pero, incluso en este último caso, ambos cónyuges tendrán perfecto conocimiento de que esa división de bienes, que constituye punto de partida en su relación matrimonial, se prolongaría no sólo durante el matrimonio, sino incluso una vez que éste concluya, eventualmente, por divorcio.

En este último caso, la división de patrimonios se mantendrá incólume, más allá de alguna eventual obligación indemnizatoria que pudiera asignarse en beneficio de alguno de los cónyuges, si es que nos encontráramos ante el supuesto en el que la relación matrimonial se hubiese destruido por culpa de uno de ellos.

Es evidente que si nos halláramos frente al supuesto de separación convencional, no habrá lugar a indemnización alguna.

\section{LOS EFECTOS HEREDITARIOS ENTRE LOS CÓNYUGES Y SU RELACIÓN CON EL RÉGIMEN PATRIMONIAL ESCOGIDO}

Conforme a lo establecido por el artículo 723 del Código Civil, «la legítima constituye la parte de la herencia de la que no puede disponer libremente el testador, cuando tiene herederos forzosos».

El artículo 724 del referido cuerpo legal, se encarga de precisar que «son herederos forzosos los hijos y los demás descendientes, los padres y los demás ascendientes, el cónyuge o, en su caso, el integrante sobreviviente de la unión de hecho».

Es necesario precisar que el texto actual del artículo 724 responde a la modificación dispuesta por el artículo 5 de la ya mencionada Ley n. ${ }^{\circ} 30007$.

Siempre ha constituido tema pacífico el relativo al derecho sucesorio del cónyuge.

Es más, no recuerdo haber leído artículo académico alguno en el Perú, que cuestione el derecho a heredar entre cónyuges.

Sin embargo, existe un aspecto sobre el que no se ha meditado en absoluto y es el referido a la relación que puede hacerse entre el derecho a heredar y el régimen patrimonial escogido por los cónyuges.

En otras palabras, lo que quiero decir es si debería o no influir en la discusión acerca de la sucesión del cónyuge, el régimen patrimonial que los esposos hayan definido antes de la celebración del matrimonio o durante la vigencia del mismo.

La pregunta concreta gira en torno a si el régimen de separación de patrimonios podría o no plantear la hipótesis de la exclusión del cónyuge de la sucesión en calidad de heredero forzoso.

Tal como está regulado en la actualidad el régimen sucesorio, al respecto no cabe la existencia de variante alguna, dado que todos los preceptos sucesorios en torno a la legítima y a los herederos forzosos, son normas de carácter imperativo, sobre las cuales no cabe pacto en contrario. 
Dentro de tal orden de ideas, no hay duda de que los cónyuges son herederos forzosos entre sí, independientemente del régimen patrimonial que existía en su matrimonio.

Eso significa que serán tan herederos forzosos los cónyuges cuyo régimen patrimonial era el de sociedad de gananciales, como aquéllos cuyo régimen patrimonial era el de separación de patrimonios.

Dentro de este razonamiento, cabría plantear la pregunta de si la existencia de un régimen de separación de patrimonios, no podría conllevar la voluntad implícita de los cónyuges para que sus patrimonios no se mezclen ni en vida ni después de ella.

Es claro que los conceptos tradicionales relativos a la separación de patrimonios, sólo plantean la autonomía de tales patrimonios mientras dure la vida del cónyuge titular de los mismos.

Así, cuando fallezca uno de los cónyuges, el otro lo heredará.

Todo ello, naturalmente, conforme a lo dispuesto por el artículo 816 del Código Civil, relativo a los órdenes sucesorios.

Dicha norma establece que: «son herederos del primer orden, los hijos y demás descendientes del segundo orden, los padres y demás ascendientes; del tercer orden, el cónyuge o, en su caso, el integrante sobreviviente de la unión de hecho; del cuarto, quinto y sexto órdenes, respectivamente, los parientes colaterales del segundo, tercer y cuarto grado de consanguinidad.- El cónyuge o, en su caso, el integrante sobreviviente de la unión de hecho también es heredero en concurrencia con los herederos de los dos primeros órdenes indicados en este artículo».

Suena lógico que el cónyuge sea considerado como heredero del tercer orden.

Ello equivaldría a decir que el cónyuge supérstite se convertiría en heredero universal, única y exclusivamente en caso el cónyuge causante no tuviere ni hijos (o demás descendientes) o padres (o demás ascendientes).

No formulamos objeción alguna a que, independiente del régimen patrimonial en el que hubieren vivido, las consecuencias hereditarias deban ser las descritas y que el cónyuge supérstite pase a constituirse en heredero universal.

Decimos esto, pues no existen patrimonios familiares en conflicto; $y$, por tanto, resulta lógico que el cónyuge supérstite unifique en el suyo el patrimonio que le pertenecía al cónyuge causante.

Lo mismo podríamos decir cuando el cónyuge supérstite concurra con herederos del primer orden; es decir, con hijos o nietos del causante; naturalmente, asumiendo que tales descendientes también son descendientes comunes del cónyuge supérstite.

Hacemos esta salvedad, pues podríamos pensar en la lógica que tendría que quienes se casen con el régimen de separación de patrimonios, lo hagan, precisamente, con el objetivo de no causar problemas a sus descendientes, personas que bien podrían ya existir antes de la celebración de ese matrimonio.

Éste sería el típico caso de un hombre y una mujer de más de cincuenta años, que contraigan entre sí, las que para ambos serían segundas nupcias; y que ambos ya tengan hijos fruto de sus primeros matrimonios, uniones de hecho $u$ otras relaciones extramatrimoniales.

En este caso, podría ser voluntad de ambos el casarse con separación de patrimonios, precisamente, para evitar problemas con respecto a lo adquirido en buena parte de la vida útil de 
esas personas; pero no podemos negar que cuando fallezca uno de los cónyuges, se planteará el problema, pues del patrimonio de este último, serán herederos forzosos tanto sus propios hijos como su cónyuge, quien concurrirá heredando una hijuela.

Entonces, el patrimonio que se quiso mantener separado del otro cónyuge en el matrimonio, ya no se seguirá manteniendo separado a la muerte del cónyuge causante, pues al concurrir el cónyuge supérstite con los hijos como herederos forzosos, hará que el cónyuge supérstite adquiera parte de la sociedad y los bienes que le pertenecían a la primera familia del cónyuge causante.

Esta situación hereditaria, regida por normas que —como hemos dicho- son de orden público, genera en la práctica muchos problemas, los mismos que no comienzan con la muerte, sino en la propia relación matrimonial, a pesar de la existencia de separación de patrimonios, pues resultará muy difícil para los cónyuges, el establecer algún mecanismo jurídico válido para lograr que los bienes adquiridos antes de la vigencia del segundo matrimonio, sean transferidos, finalmente, a manos exclusivas de los hijos procreados en el primer matrimonio.

Nótese, incluso, que la figura del anticipo de legítima no resultaría suficiente para solucionar el problema, ya que si se pensara en anticipar todos los bienes a los hijos, tal anticipo sólo se podría hacer válidamente, antes de contraer las segundas nupcias, pues luego de contraídas éstas, no se podría preterir los futuros derechos hereditarios del otro cónyuge, despojándolo de cualquier expectativa hereditaria futura, con respecto al patrimonio ya adquirido por el otro cónyuge antes de la celebración del segundo matrimonio.

Además, todo lo que adquieran los cónyuges como bienes propios, durante la vigencia del segundo matrimonio, podrá generar legítimas expectativas hereditarias, no sólo en los hijos de cada una de esas personas, sino también en el segundo cónyuge.

Esta situación se ha agravado con la dación de la Ley $n .^{\circ} 30007$, la misma que ha ampliado los efectos sucesorios del cónyuge, a los concubinos o miembros de uniones de hecho, que hubieren cumplido con los requisitos establecido en el artículo 326 del Código Civil. ${ }^{6}$

Por lo demás, el Código no se pronuncia con respecto al pacto de separación de patrimonios en casos distintos al matrimonio, concretamente en lo que respecta a las uniones de hecho.

\section{Nos explicamos.}

Si de acuerdo al artículo 326, la unión de hecho genera a partir del segundo año de convivencia, los efectos de la sociedad de gananciales, la pregunta que corresponde formular es si resultaría válido que los concubinos antes de cumplir esos dos años de convivencia, otorguen una escritura pública de separación de patrimonios, a efectos de que una vez cumplidos esos dos años, su régimen patrimonial no sea el de sociedad de gananciales, sino el de separación de patrimonios.

6 «Artículo 326.- La unión de hecho, voluntariamente realizada y mantenida por un varón y una mujer, libres de impedimento matrimonial, para alcanzar finalidades y cumplir deberes semejantes a los del matrimonio, origina una sociedad de bienes que se sujeta al régimen de sociedad de gananciales, en cuanto le fuere aplicable, siempre que dicha unión haya durado por lo menos dos años continuos. La posesión constante de estado a partir de fecha aproximada puede probarse con cualquiera de los medios admitidos por la ley procesal, siempre que exista un principio de prueba escrita. La unión de hecho termina por muerte, ausencia, mutuo acuerdo o decisión unilateral. En este último caso, el juez puede conceder, a elección del abandonado, una cantidad de dinero por concepto de indemnización o una pensión de alimentos, además de los derechos que le correspondan de conformidad con el régimen de sociedad de gananciales. Tratándose de la unión de hecho que no reúna las condiciones señaladas en este artículo, el interesado tiene expedita, en su caso, la acción de enriquecimiento indebido. Las uniones de hecho que reúnan las condiciones señaladas en el presente Artículo producen, respecto de sus miembros, derechos y deberes sucesorios, similares a los del matrimonio, por lo que las disposiciones contenidas en los artículos 725, 727, 730, 731, 732, 822, 823, 824 y 825 del Código Civil se aplican al integrante sobreviviente de la unión de hecho en los términos en que se aplicarían al cónyuge». 
A pesar del silencio de la norma, ello es perfectamente posible, ya que la disposición del artículo 326 en torno al régimen patrimonial, no constituye un precepto de orden público, siendo impensable que se sostenga que los concubinos carezcan del derecho a escoger el régimen patrimonial que prefieran.

Por lo demás, también nos queda claro que, en ausencia de norma legal al respecto, resultan aplicables al caso de las uniones de hecho, mutatis mutandis, las disposiciones del Código Civil relativas a la posibilidad de cambiar de régimen patrimonial, en caso se hubiere iniciado la unión de hecho, una vez cumplidos los dos primeros años de convivencia, con un régimen patrimonial de sociedad de gananciales.

Lo que estamos diciendo es que, en este caso, sería posible que los concubinos liquiden la sociedad de gananciales y celebren una escritura pública de separación de patrimonios, sustituyendo un régimen por otro en su unión de hecho.

Entonces, hemos dejado sentado que la elección del régimen patrimonial, básicamente, es la misma, tanto en el matrimonio como en las uniones de hecho. Si bien es cierto que en ambas se parte de la presunción de una sociedad de gananciales, tanto los esposos como los miembros de las uniones de hecho, podrían preferir regirse por la separación de patrimonios.

Como hemos señalado, la Ley $n .^{\circ} 30007$, extiende a los concubinos los derechos sucesorios de los cónyuges, en calidad de herederos forzosos.

Estos efectos sucesorios, en la actualidad se presentan, sin admitir prueba en contrario, dada la naturaleza de orden público de las normas que rigen la sucesión, tanto de las parejas que tienen régimen de sociedad de gananciales como régimen de separación de patrimonios.

\section{CONCLUSIONES: NUESTRA PROPUESTA}

¿Y qué es lo que queremos plantear, finalmente, luego de todas estas consideraciones?

Lo que queremos proponer es que el régimen de separación de patrimonios pueda sufrir una modificación legislativa, que implique agregar una opción al mismo, que consistiría en que la separación de patrimonios se siga manteniendo después de la muerte del titular de dicho patrimonio. Ello significa que, de optarse por este camino, los cónyuges podrían convenir casarse bajo separación de patrimonios y también renunciar a suceder entre sí.

Ello equivaldría a la existencia legal de tres regímenes, tanto patrimoniales como sucesorios en relación al cónyuge o concubino:

a) Régimen patrimonial de sociedad de gananciales y derecho a sucesión recíproca de los cónyuges o concubinos como herederos forzosos del tercer orden. El aspecto sucesorio de este régimen no admitiría pacto en contrario.

b) Régimen patrimonial de separación de patrimonios y derecho a sucesión recíproca de los cónyuges y concubinos. Si no hubiese pacto en contrario, los cónyuges seguirían siendo herederos forzosos del tercer orden.

c) Régimen patrimonial de separación de patrimonios y pacto de renuncia a sucesión recíproca de los cónyuges y concubinos. De esta forma, si hubiese pacto en contrario, los cónyuges dejarían de ser herederos forzosos del tercer orden.

Consideramos que resultaría conveniente establecer esta modificación legislativa, ya que ella podría preservar la separación de patrimonios, cuando los cónyuges o concubinos así lo deseen, 
evitando — con un pacto de esta naturaleza - conflictos entre los descendientes de anterior o anteriores familias o relaciones y el cónyuge o concubino supérstite.

Está claro, por lo demás, que podríamos no sólo estar en presencia de descendientes fruto de una relación previa al matrimonio, sino de varias de ellas.

Las relaciones de familia pueden terminar siendo muy complicadas y las expectativas hereditarias en donde confluyan, incluso, los intereses del cónyuge supérstite, ocasionan, en muchos casos, problemas tan serios, que preferiríamos que en estos supuestos - y por excepción- el carácter de heredero forzoso del cónyuge se relativice.

En buena cuenta, el cónyuge supérstite sólo tendría carácter de heredero forzoso en los supuestos a) y b) precedentes, pero no en el supuesto c).

Esto no impide, por cierto, que el cónyuge causante pueda ulteriormente instituirlo como heredero voluntario, a pesar de haber acordado el régimen de separación de patrimonios, con pacto de exclusión de heredero forzoso del cónyuge supérstite.

Admitiendo que tal situación sería algo contradictoria, ella revestiría plena validez.

En la eventualidad de que se quiera cuestionar nuestro planteamiento señalando que con este pacto se estaría dejando desamparado en materia hereditaria al cónyuge o concubino supérstite, no debemos olvidar que ellos pactaron separación de patrimonios.

Esta tercera modalidad de régimen patrimonial y hereditario, estaría otorgando a la separación de patrimonios, un alcance adicional del que habitualmente tiene.

Decimos esto, pues la separación de patrimonios se extiende solamente a los patrimonios de los cónyuges mientras éstos vivan. En cambio, con la modalidad c), antes propuesta, la separación de patrimonios se extendería, incluso, después de la muerte.

Ello no nos preocupa, en la medida de que si se hubiese pactado el régimen de separación de patrimonios, los cónyuges tendrían bienes propios que proteger, y lo que estamos haciendo con esta propuesta, es prolongar tal protección, más allá del término de sus respectivas vidas.

Creo firmemente en la legítima hereditaria; creo también en que ella evita la desprotección de los intereses y los derechos de los más débiles, y por eso siempre he defendido la permanencia de la legítima dentro del Derecho sucesorio peruano.

Sin embargo, nos encontramos ante un supuesto muy especial, con características particularmente definidas, y en donde no estaríamos desprotegiendo los intereses de nadie.

\section{REFERENCIAS}

- CASTILLO FREYRE, Mario. La sucesión en las uniones de hecho.(2013). En: Persona y familia. Revista del Instituto de la Familia-Facultad de Derecho. Lima: Universidad Femenina del Sagrado Corazón, n. ${ }^{\circ} 2$ (1), pp. 21-41.

- CASTILLO FREYRE, Mario y Ricardo VÁSQUEZ KUNZE. (2006). Amor de gavilanes. Mujer, casos de la vida real: discriminación, disposición y gravamen de los bienes sociales. En: Analizando el análisis. Autopsia del análisis económico del derecho por el derecho civil. Lima: Pontificia Universidad Católica del Perú-Estudio Mario Castillo Freyre. 